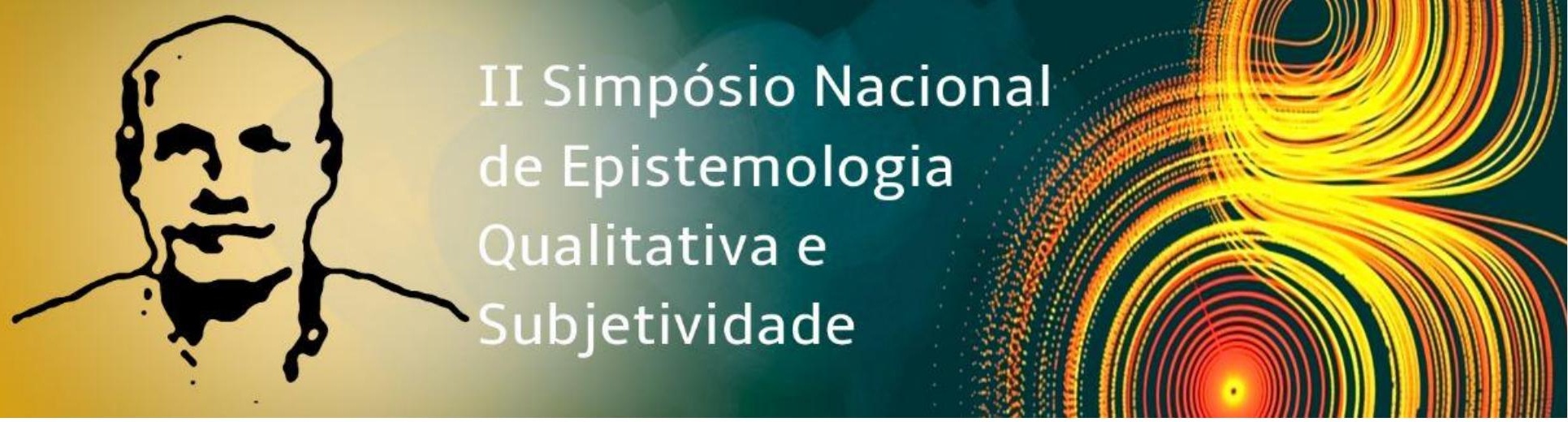

Eixo temático: Teoria da subjetividade: discussões conceituais e relações com outros referenciais teóricos.

\title{
AS DIMENSÕES DO SER E DE SER: A SUBJETIVIDADE QUE TOCA A PELE
}

ALEMEIDA, Julia Lino de - UnB, lino.juh@gmail.com

\section{Resumo:}

Este trabalho visa apontar a percepção do sujeito no processo de ensino-aprendizagem. Desta forma, venho apresentar, além de aspectos teóricos e pedagógicos, uma visão pluridimensional deste sujeito que aprende na atual época - de forma a enxergar a aprendizagem de uma maneira mais complexa. Em vista disto, proponho primeiramente apresentar a Teoria do Sujeito e da Subjetividade, elaborada por Fernando González Rey ${ }^{1}$ (2003). Em seguida irei apresentar as contribuições dos saberes teatrais para que possamos enxergar de forma mais profunda os processos de ensino-aprendizagem do ser humano.

Palavras-chave: educação, subjetividade, teatro

\section{SOBRE A TEORIA DO SUJEITO E DA SUBJETIVIDADE}

Recebemos como herança uma concepção secular, segundo o qual o homem é um ser cindido entre razão e emoção (LEITE, 2008, p.16). Também influenciada por estas questões, a psicologia cognitiva e o behaviorismo, acreditavam que recursos externos à pessoa podiam ser moldados para produzir determinado comportamentos num caso e operações de processamento no outro (GONZÁLEZ REY, 2014, 37).

A epistemologia positivista e realista, base sobre o qual se erigiram tanto o behaviorismo quanto a psicologia cognitiva, estava centrada nos dados e na informação. No caso do behaviorismo, o comportamento sempre foi identificado como reação, sem caracterização de uma natureza própria além da concretização do ato, seja num plano externo ou interno, definia o comportamento. Logo que o esquema estimulo-resposta foi sucedido pelo esquema da relação de variáveis, o conceito de operacionalização passou a ter um lugar fundamental para atribuir objetividade às variáveis, que deveriam ser definidas por atributos concretos que permitissem a sua

\footnotetext{
${ }^{1}$ É professor titular do Centro Universitário de Brasília (CEUB) na área de psicologia e professor sênior da Faculdade de Educação da Universidade de Brasília. Doutor em Psicologia pelo Instituto Geral e Pedagógico de Moscou, em 1979. Doutor em Ciências, pelo Instituto de Psicologia da Academia de Ciências da União Soviética, em 1987. (MARTÍNÉZ; ÁLVAREZ, p.236)
} 


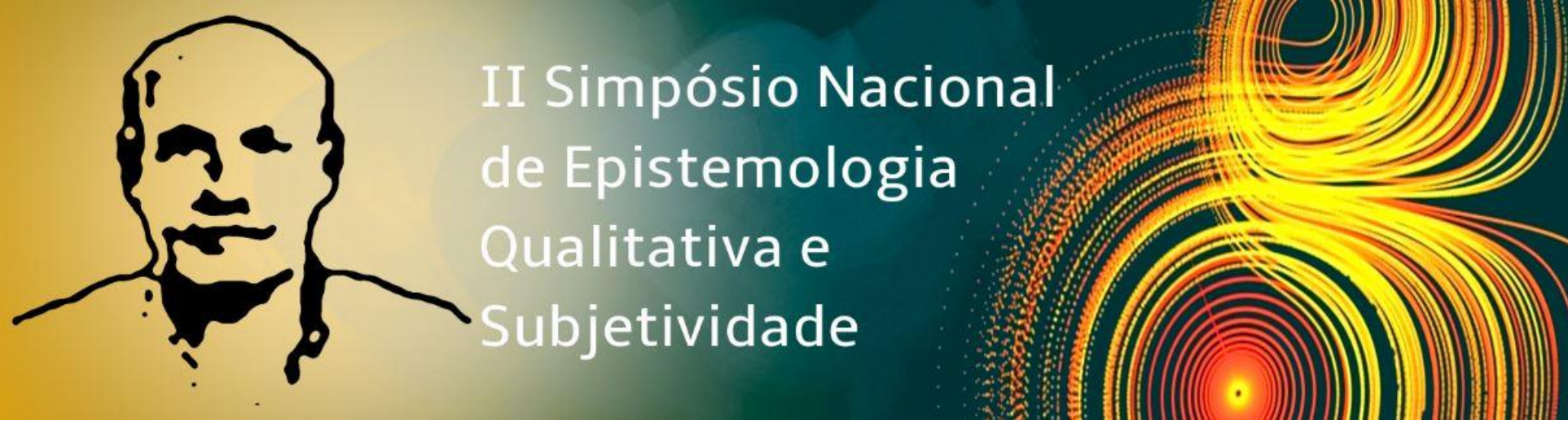

mediação. Em ambas as versões da psicologia comportamental, o homem era explicado mediante externos a ele; num caso pelos estímulos, que representavam o ambiente que definia o comportamento e, no outro, pelas variáveis que sempre explicavam, em nível estatístico, a possível ocorrência de um tipo de comportamento defino como variável dependente, algo que em campos de tecnologia como a medicina continua sendo critério central para tomada de decisões (GONZÁLEZ REY, 2014, p.36).

González Rey, completa esse pensamento dizendo que a falta do conhecimento da origem cultural da mente fez com que essas psicologias não apresentassem o conhecimento como uma representação de uma realidade construída e sim como uma realidade dada, de modo que a explicação sobre o homem advinha de um mundo externo a ele, onde se excluiu os afetos, as relações humanas e a cultura. Desta forma, essas psicologias não enxergavam a realidade humana como construída, pois seus estudos para entender as funções e as operações humanas partiam de um mundo externo naturalizado, onde se constituía a divisão entre o sujeito-objeto. Essa divisão permite então o reconhecimento da cientificidade no método em questão, ou seja, o estudo se direciona ao objeto e não ao sujeito.

Partindo deste princípio González Rey (2014, p, 38), explana sobre a impossibilidade de se avançar de forma consequente no estudo das funções psíquicas como produções subjetivas sem uma mudança de paradigma, em que o caráter subjetivo gerador do ser humano e o reconhecimento da cultura como realidade inventada sejam plenamente assumidos.

$\mathrm{Na}$ Teoria do Sujeito, o conceito de subjetividade é compreendido de maneira indissociável da natureza cultural. Deste modo, a compreensão sobre a psique se torna mais profunda e complexa, uma vez que, a mesma perde seu caráter estático e definido para ser considerada como um complexo sistema recursivo em constante desenvolvimento. (GOULART, 2013, p.27)

A partir disto, González Rey considera que a subjetividade:

[...] não é apenas a psique humana. A subjetividade é o nível da psique que se configura na vida cultural do homem. Portanto, na minha visão que parte de um autor que pela primeira vez trouxe o tema da cultura para a representação da mente, que foi Vygotsky, em bora se nós analisarmos as diferentes tendências da psicologia a própria psicanálise, o humanismo, todas elas tenham mantido uma tendência a evoluir de uma ideia de natureza humana a uma ideia de produção da subjetividade em condições da sociedade e da cultura. Por que precisamente a forma em que o termo subjetividade circula no senso comum, e com grande frequência nos próprios especialistas, está associando a subjetividade a aquilo que pertence ao indivíduo, que está no intrapsíquico, que faz uma mente individual. Ou seja, existe uma ideia de associar a subjetividade com individualidade, com psique, com fenômenos intrapsíquicos [...] A subjetividade traz uma ideia da psique humana que não apenas se apresenta nos aspetos psíquicos individuais, mas apresenta nos processos psíquicos que acontecem nos espaços sociais. Ou seja, a forma que eu venho desenvolvendo este campo da subjetividade na perspectiva histórico cultural, ela representa a subjetividade simultaneamente na organização individual das pessoas , que é o que eu chamo de subjetividade individual e na organização dos diferentes espaços sociais, ou 


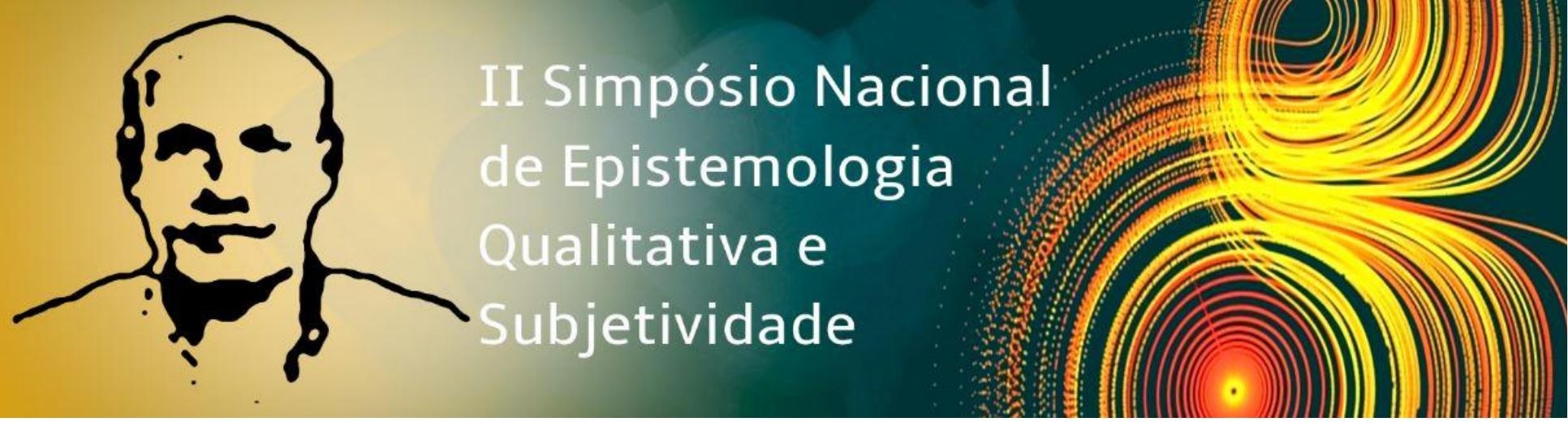

seja, a sociedade tem uma dimensão subjetiva que não é soma das subjetividades dos indivíduos, é uma produção que acontece pelos processos discursivos ,imaginários, relacionais que acontecem no espaço social ${ }^{2}$

A subjetividade promove a integralização entre o indivíduo e a sociedade, de modo em que ambos emerjam em momentos tanto da subjetividade individual quanto na subjetividade social. Essas duas subjetividades são relacionais, onde são constituídas e constituintes uma pela outra. O indivíduo cria os seus sentidos subjetivos provenientes da sua experiência social, uma vez que, nenhuma atividade humana resulta em uma atividade isolada do conjunto de sentidos que caracterizam o mundo histórico social da pessoa. (GONZÁLEZ, 2014)

Dentro deste delineamento teórico, a aprendizagem é compreendida como um processo subjetivo complexo, onde de fato o sujeito pode se expressar e assumir seu caráter ativo em sala de aula, ou seja, não se deter apenas a assimilação da informação e sim na produção personalizada, portanto subjetiva, desta informação.

Ao se falar em subjetividade, pode-se pensar que esta temática já está esgotada, pois muito já se discutiu sobre este tema em educação. Porém as discussões pedagógicas que levam em consideração a subjetividade no processo de ensino-aprendizagem, em sua maioria, associam o termo subjetividade como uma produção de sentido individualizado e hermético do ser humano. Durante muitos anos as ciências sociais dividiram seus estudos entre a individualidade do homem e a sociedade. Ou seja, a compreensão sobre o ser, mais uma vez historicamente se constitui de forma fragmentada, o que impossibilitou sua compreensão de maneira mais profunda, já que não podemos compreender a cultura sem o homem como também não podemos compreender o homem sem a sua cultura.

Tendo em vista a importância da subjetividade para o desenvolvimento humano e os impactos que a mesma tem na aprendizagem, acredita-se:

[...] que nenhuma condição ou experiência humana em seus atributos objetivos define de forma linear seu impacto na aprendizagem e no desenvolvimento da pessoa, pois o impacto sempre será produzido em função dos recursos subjetivos a pessoa e pela forma como ela se posiciona frente a situação vivida. A compreensão da subjetividade nesta perspectiva defende que a constituição psíquica da pessoa está permanentemente com suas ações em cada um dos momentos e espaços de suas vidas. Esse ponto leva a compreender a pessoa como sujeito de posicionamentos ativos que são partes inseparáveis de sua produção subjetiva no curso de sua experiência (MARTÍNEZ, ÁLVAREZ, 2014, p. 10).

\footnotetext{
${ }^{2}$ Fala retirada, via internet da Palestra oferecida no III Ciclo de Conferências: "Um olhar plural - simbolismo no campo dos estudos organizacionais". Programa de Pós-Graduação em Administração da Universidade Federal do Espírito Santo. 24 de agosto de 2007. Acessado em: 14/05/2015.
} 


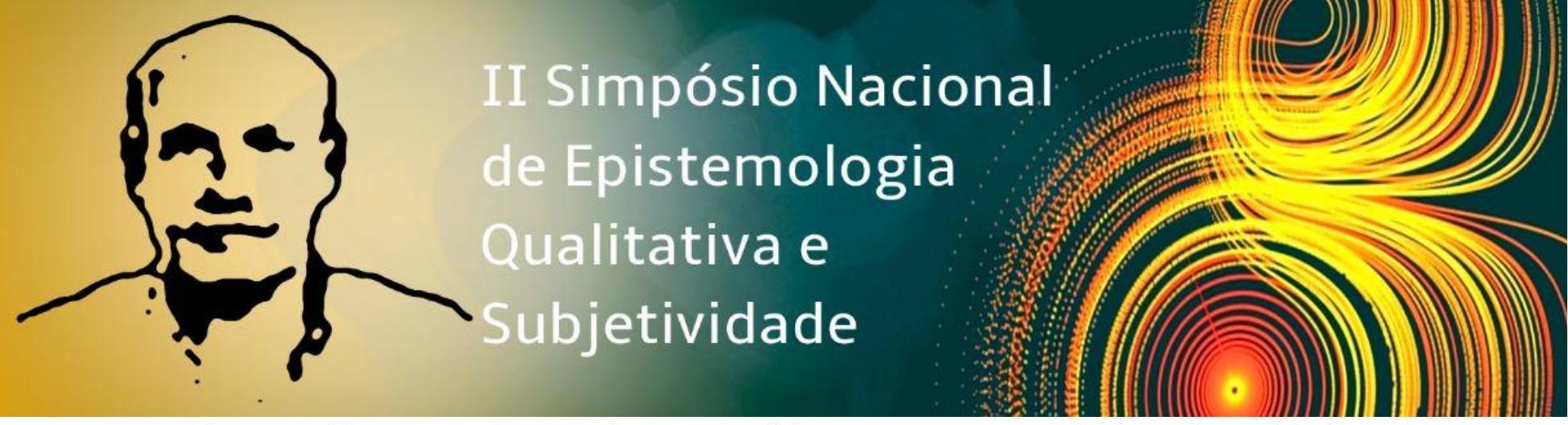

Neste sentido, a aprendizagem é compreendida como uma expressão de caráter subjetivo da vida do educando, onde essa subjetivação aparece no próprio processo de aprender, de modo que a mesma assume um caráter de configuração subjetivo organizado, a partir da situação conjuntural e relacional na qual a aprendizagem ocorre (GONZÁLEZ, 2014). Ou seja, essa perspectiva abre espaço para que, o indivíduo seja capaz de gerar uma relação própria e personalizada no contexto no qual está inserido.

A subjetividade é a geradora da produção simbólica-emocional da experiência. González Rey (2014), afirma que toda forma de conhecimento é uma produção subjetiva e pode ser considerado libertadora, sadia e facilitadora do desenvolvimento. Diante disto, a afetividade é compreendida na aprendizagem não apenas como uma qualidade do processo, ela se torna inerente a ele.

Meira Piloto, em seu livro ARTE, AFETO E EDUCAÇÃO: a sensibilidade na ação pedagógica, explica que cria-se uma aliança entre a educação e a psicologia para o desenvolvimento de estudos e pesquisas, que objetivam a reflexão, junto ao contexto sociocultural, da importância de se humanizar o conhecimento para que haja o desenvolvimento simultâneo de aspectos cognitivos e afetivos na escola.

As discussões acerca da afetividade partem de definições que não contemplam a sua magnitude. Meira Piloto (2010) define a afetividade como como um sentimento de agrado e desagrado. Já Silva Leite (2008), citando Dér, (input 2004, p. 61) define a afetividade como um conceito que além de envolver um componente orgânico, corporal, motor e plástico, que é a emoção, apresenta também um componente cognitivo, representacional, que são os sentimentos e a paixão. Silva Leite ainda relata que o afeto possibilita configurar a emoção em sentimento e sua representação no plano interno, assim a emoção passa a interferir na atividade cognitiva, possibilitando seu avanço. Este autor, mesmo discutindo o afeto, numa perspectiva históricocultural, ainda o retém como um advento da cognição e onde é constituído por processos cognitivos da pessoa.

É comum encontrarmos discussões sobre a afetividade como um acontecimento emocional isolado, porém não podemos esquecer que a mesma está interligada a inteligibilidade subjetiva e não pode ser considerada apenas um advento emocional repentino, uma vez que, a afetividade está relacionada a redes complexas da psique humana.

Os vínculos afetivos desenvolvidos do âmbito escolar fazem com que o aluno se reconheça em meio a aprendizagem, provocando assim, um impulso a um processo intenso de camadas de sentido que demandam a utilização dos recursos simbólicos-subjetivos deste sujeito.

A partir desses posicionamentos sobre a importância do afeto e sobre esse sujeito ativo e indissociável da sua natureza cultural, A Teoria do Sujeito, defende a imaginação como o papel central das produções intelectuais humanas. González Rey (2014), considera que a imaginação indica o caráter subjetivo de uma produção humana, o qual, mais que um empecilho

\section{BRASÍLIA, 22 a 25 DE OUTUBRO DE 2019 CENTRO UNIVERSITÁRIO DE BRASÍLIA - UNICEUB}




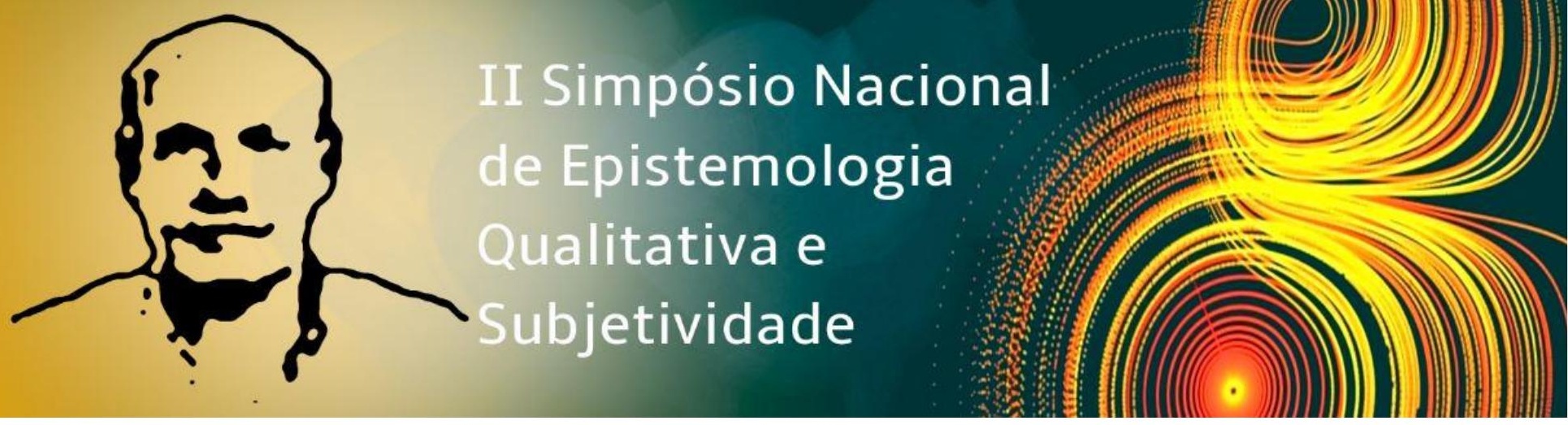

Atualmente, como visto, existem pesquisas que mostram que a subjetivação é o meio pelo qual se produz toda a forma de conhecimento e que a mesma é a geradora do campo simbólico-emocional do sujeito. Mas o que o teatro tem a ver com isso? O teatro é meio pelo qual suscita em tempo integral processos de subjetivação, requerendo o uso do campo simbólico tanto individual quando social do homem - de modo a propiciar a criação e ampliação das camadas de sentido do sujeito.

Partindo desse princípio, os processos de subjetivação adquiridos em um estado de criação propiciam uma dimensão e estruturas diferenciadas no momento em que são corporificados. Neste momento de criação não há espaço para a dicotomia entre o corpo e mente, entramos em um discurso dialético onde a subjetivação do indivíduo serão corporificadas e essas próprias corporificação criarão outros processos de subjetivação que serão outra vez corporificados e assim por diante.

Fayga Ostrower (2001), em seu livro Criatividade e Processos de Criação, onde tem o seu enfoque no Ser Humano criativo, a criatividade é considerada como um potencial inerente ao homem, e a realização desse potencial uma de suas necessidades (p.5).

O potencial criador elabora-se nos múltiplos níveis do ser sensível-cultural-consciente do homem, e se faz presente nos múltiplos caminhos em que o homem procura captar e configurar as realidades da vida. Os caminhos podem cristalizar-se e as vivencias podem integra-se em formas de comunicação, em ordenadas concluídas, mas a criatividade como potência se faz sempre. A produtividade do homem, em vez de se esgotar, liberando-se, se amplia. (p.26)

Segundo a autora, os comportamentos criativos do homem têm como base a integralização do consciente, sensível e cultural. Nesta visão, o ser é sensível e consciente em qualquer contexto cultural, de forma que a sensibilidade e a consciência são qualidades comportamentais inatas do ser humano. É importante considerarmos estes estados de consciência e de sensibilidade, como algo não estático, obsoleto, de maneira que se estimulados podem se expandir. Já a cultura, nesta visão, representa o desenvolvimento social do homem; configura as formas de convívio entre as pessoas. (FAYGA,2011, p. 11)

Desta forma, o estado criação teatral, propicia a ampliação das experiências do ser humano enquanto ser sociocultural, uma vez que, o teatro possibilita ao aluno uma vivência cotidiana e extra cotidiana sobre a sua realidade. Essas vivências, ainda atingem um nível maior, visto que são conquistadas num sentindo mais amplo e não se restringem a apenas ao indivíduo. É no fazer teatral que a corporificação da subjetivação se constitui em meio sensibilização da comunicação estética dessas novas vivências e subjetividades. Neste sentindo 


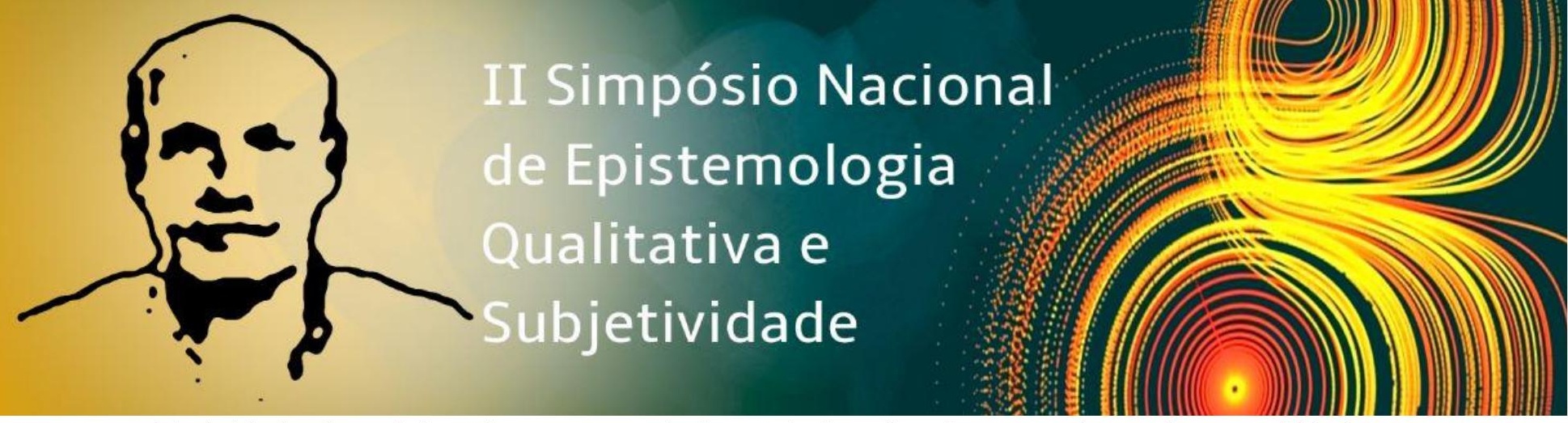

a subjetividade do sujeito alcança um nível sensível, cultural e consciente dessa realidade vivida.

[...] O grande poder do teatro, por sua vez, está no fato de que é só dentro dele que eu tenho condições de, corporalmente, assumir um mundo fictício. É só no teatro que eu tenho a possibilidade de emprestar o meu corpo para tornar presente, diante de outros, um ser ausente. (PUPO, 2010, p. 12)

Este corpo em estado de criação, assume outras realidades e outras vivências que trazem a noção de alteridade, ou seja, o teatro é uma arte que permite ao indivíduo um conhecimento maior sobre o mundo, já que ele possibilita sair de mim e ver o ponto de vista de outro (PUPO, 2010, p. 12).

Esses estados mencionados até aqui, alcançam possibilidades ainda maiores se pensarmos que este corpo criativo está comunicando algo a alguém, ou seja, estes estados não são adventos isolados de um sujeito em que a sua prática teatral é para ele mesmo, pelo contrário a prática teatral faz com que este sujeito apenas crie, mais que a partir de seu corpo, comunique a sua criação de forma estética. Ou seja, o aprendente tem a sua prática observada onde assume o papel de comunicador e em outra hora inverte-se os papéis, onde aquele que comunica é inserido ao viés da recepção da prática de um outro alguém.

Ainda pensando sobre a importância da criação, produção e recepção na disciplina de teatro, mostrarei agora os ensinamentos da cena e as contribuições dos pensamentos de Eugênio Barba para a educação, desta forma para uma melhor visualização destes ensinamentos na educação, sempre que o autor se referir ao espectador e ao ator colocarei a palavra estudante ao lado.

Barba enxerga o espetáculo teatral como um organismo vivo e expõe a importância de primeiro se compreender os níveis de organização de um espetáculo como um todo para depois se compreender a relação entre as suas partes isoladas. Os três níveis de organização do espetáculo que apareceram de forma evidente para Barba são: o nível da dramaturgia orgânica, ou dinâmica, que é o nível primordial para se criar dinamismo, ritmo, ações físicas e vocais dos atores/estudantes para estimular sensorialmente a atenção dos espectadores; o nível da dramaturgia narrativa, que é os acontecimentos que orientam o espectador/estudante sobre os vários sentidos ou vários sentidos que o espetáculo pode conter, e por último temos o terceiro nível, a dramaturgia evocativa, que é a forma inconsciente de capturar significados involuntários e ocultos do espetáculo específico para cada espectador/estudante.

Estes três tipos de organização estão ligados ao espectador/estudante, de maneira a considera-lo como ativo em sua recepção. Ainda pensando neste espectador/estudante, Barba ainda criou a dramaturgia do espectador, que consistia em criar um espetáculo que pudesse 


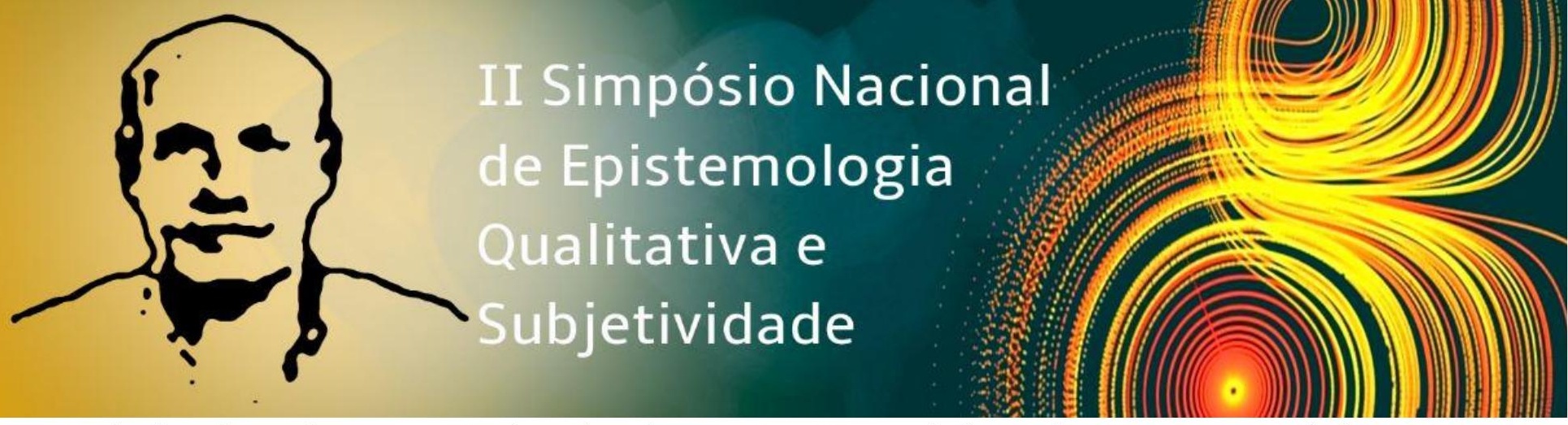

atingir cada um de seus espectadores/estudantes tanto num sentindo amplo quanto num sentindo subjetivo.

Em A Canoa de Papel, Barba descreveu os princípios necessários para desenvolver a presença cênica do ator/estudante numa perspectiva histórica e multicultural:

\begin{abstract}
O movimento de qualquer pessoa põe em jogo a experiência do mesmo movimento por parte de seu observador. A informação visual gera, no espectador, uma participação cinestesia. A cinestesia é a sensação corporal interna dos próprios movimentos e tensões e também dos movimentos e tensões dos outros. Isso quer dizer que as tensões e modificações do corpo do ator provocam um efeito imediato no corpo do espectador até uma distância de dez metros. Se a distância é maior o efeito diminui até desaparecer. Essa era uma das razões pelas quais os espectadores do Oldin eram colocados a poucos metros dos atores. (BARBA, 2010, p. 57)
\end{abstract}

Segundo Barba, o visível e o cinestésico são indissociáveis. Essa relação entre o sujeito que faz a ação e o sujeito que recebe ação, os coloca em estados de tanto imaginários quanto criativos, onde um é afetado pelo outro. Desta maneira, podemos enxergar que além do teatro propiciar novos sentidos subjetivos para a pessoa que o faz, o teatro também gera novos sentidos subjetivos para quem o assiste, onde a subjetivação afeta a recepção do que está sendo produzido esteticamente e onde os efeitos cinestésicos propiciam novas criações de subjetividade. Ou seja, não existe o espaço de dentro e o espaço de fora, existe o espaço entre os corpos.

É importante ressaltar que a cinestesia é uma das formas em que pode se afetar os espectadores. Além da sinestesia o teatro abre caminhos para a constituição de experiências que tornam a imaginação inerente a nossa prática. Mais uma vez ao se pensar na comunicação e portanto, na recepção, percebemos a formação da noção de alteridade do educando. Pois, além dos seus próprios processos imaginativos, o mesmo irá pensar em como "ativar" os processos imaginativos de quem o assiste. Ou seja, o teatro amplia e intensifica os processos imaginativos de todos os seus praticantes, de maneira que, a imaginação consiga alcançar mais camadas em seu desenvolvimento e evolua exponencialmente a produção da inteligibilidade humana.

A partir de todas essas questões por mim apresentadas, as constituições do ser e de ser, no contexto escolar fazem com que a identidade, sensibilidade, criticidade e a noção de pertencimento sejam parte do processo de aprender. Afinal "A mente criativa brinca com os objetos de que ama" (Carl Jung).

\title{
REFERÊNCIAS
}




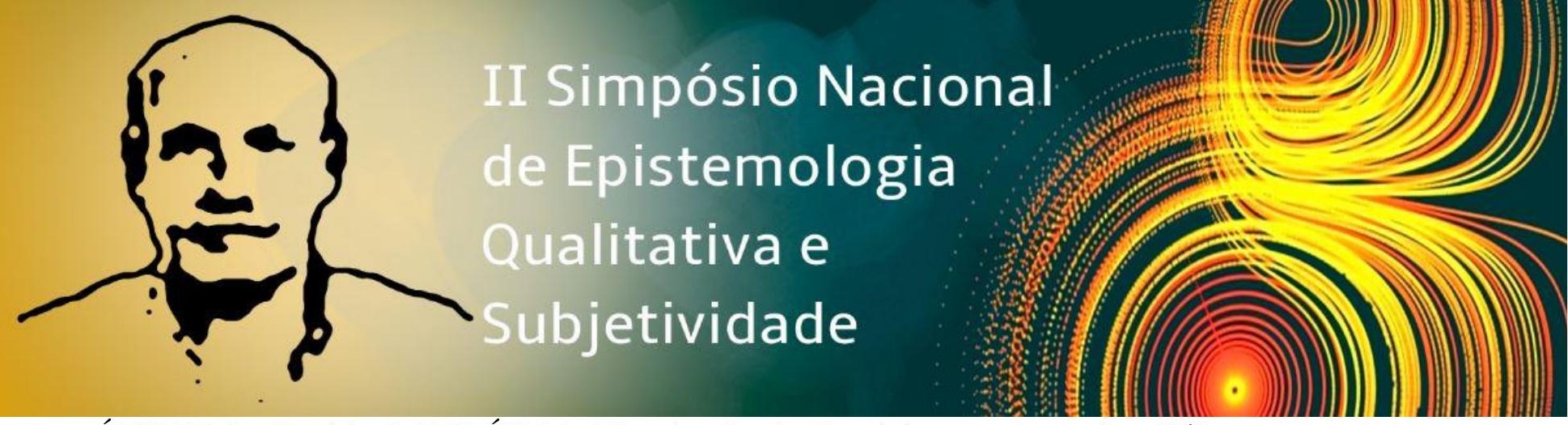

ÁLVAREZ, Patrícia, MARTÍNEZ, Albertina (org). O sujeito que aprende: diálogo entre a psicanálise e o enfoque histórico cultural. Brasília: Liber Livros, 2014.

BOAL, Augusto. A estética do oprimido. Rio de Janeiro: Garamond, 2009.

. O teatro do oprimido e outras poéticas políticas. Rio de Janeiro: Civilização Brasileira, 2010.

BARBA, Eugenio. A Canoa de Papel. Brasília: Dúlcina, 2009.

. Queimar a Casa: Origens de um diretor. São Paulo: Perspectiva, 2010.

CALLONI, UMBERTO. Ensino e Complexidade. In: Ernani Lampert. (Org). Educação, Cultura e Sociedade: abordagens múltiplas. 1 ed. Porto Alegre- RS: Sulina, 2004, v.1, p. 122-138.

COHEN, Renato. Performance Como Linguagem. São Paulo: Perspectiva: 2004.

DESGRANGES, Flávio. A PEDAGOGIA DO ESPECTADOR. São Paulo: HUCITEC, 2010. FARIAS, Sérgio Coelho. Condições de trabalho com teatro na rede pública de ensino. In URDIMENTO. Revista de Estudos em Artes Cênicas / Universidade do Estado de Santa Catarina. Programa de Pós-Graduação em Teatro. Vol. 01, n. 10 (Dez. 2008) Florianópolis: UDESC/CEART.

FERRACINE, Renato. Corpos em fuga, corpos em arte. São Paulo: Editora: Fapesp, 2006.

FERREIRA, Sueli (org.). O ensino das artes: Construindo caminhos. São Paulo: Papirus. 2001.

GONZÁLEZ REY, Fernando Luis. A imaginação como produção subjetiva: as ideias e os modelos da produção intelectual, in ÁLVAREZ, Patrícia, MARTÍNEZ, Albertina (org). O sujeito que aprende: diálogo entre a psicanálise e o enfoque histórico cultural. Brasília: Liber Livros, 2014. 35-63.

. Sujeito e subjetividade uma aproximação histórico cultural São Paulo:

Pioneira Thomson, 2003.

GOULART, Daniel.

INSTITUCIONALIZAÇÃO, SUBJETIVIDADE E

DESENVOLVIMENTO HUMANO: abrindo caminhos entre educação e saúde mental.

Brasília: Tese de Mestrado em Educação, UnB, 2013.

LAMPERT, Ernani, O DESMONTE DA UNIVERSIDADE PÚBLICA: A INTERFACE DE UMA IDEOLOGIA. São Paulo: 2004 


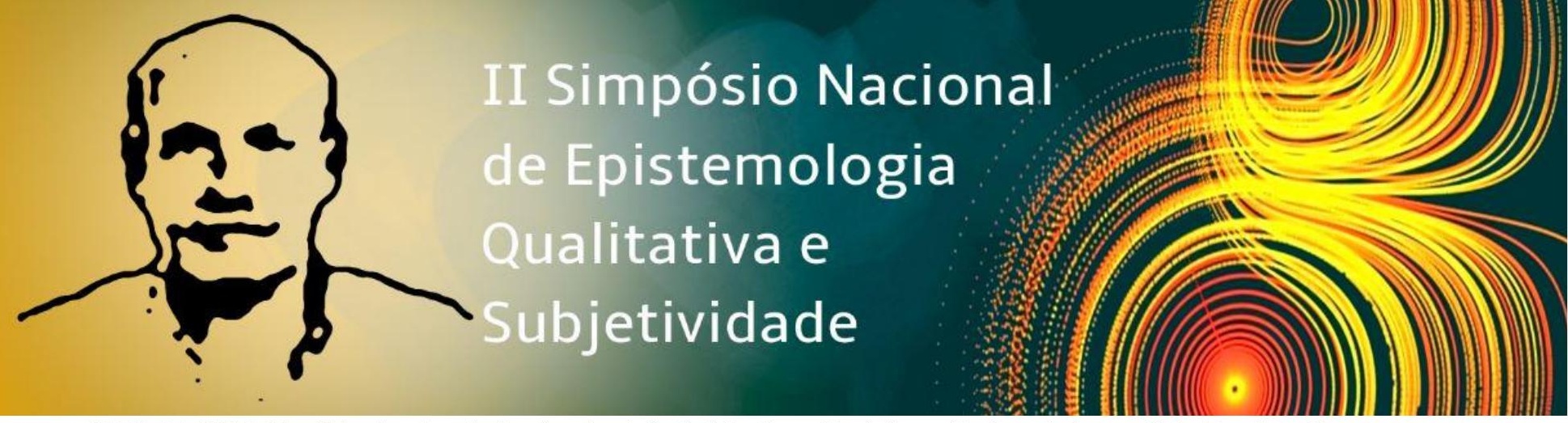

LEITE SILVA, Sérgio Antônio (org). Afetividade e Práticas Pedagógicas. São Paulo: Casa do psicólogo, 2011.

LIBÂNEO, José Carlos, A DEMOCRATIZAÇÃO DA ESCOLA PÚBLICA: a pedagogia crítico-social dos conteúdos. São Paulo: Loyola, 2001.

MEIRA, Marly; PILOTTO, Sílvia. ARTE, AFETO E EDUCAÇÃO: a sensibilidade na ação pedagógica. Editora: educação arte, 2010.

PUPO, Maria Lúcia. Teatro na escola: experiências e olhares - Teatro e educação formal. São Paulo: Fundação Athos Bulcão, 2010.

RAPOZO, Miriam; QUEIROZ, Lúcia. Modulo 4: Teorias da educação. Brasília: Dupligráfica Editora Ltda, 2008.

SAVIANI, D. O trabalho como princípio educativo frente às novas tecnologias. Petrópolis: Vozes, 1994.

SERRES, MICHEL. POLERGAZINHA. Rio de Janeiro: Bertrand Brasil, 2013.

SPOLIN, VIOLA. IMPROVISAÇÃO PARA TEATRO: Editora Perspectiva, 1979.

NACHMANOVITCH, Stephen. SER CRITIVO: O poder da improvisação na vida e na arte. São Paulo: Summus, 1993.

OSTROWER, Fayga. Acasos e Criações Artísticas. Rio de Janeiro: CAMPUS, 2001.

. Criatividade e processos de criação. Rio de Janeiro: CAMPUS, 2001.

URDIMENTO. Revista de Estudos em Artes Cênicas / Universidade do

Estado de Santa Catarina. Programa de Pós-Graduação em Teatro. Vol. 01, n. 10 (dez. 2008)

- Florianópolis: UDESC/CEART.

VILLAS BOAS, Benigna. Portfólio, avaliação e trabalho pedagógico. Campinas, Ed. Papirus, 2004. 


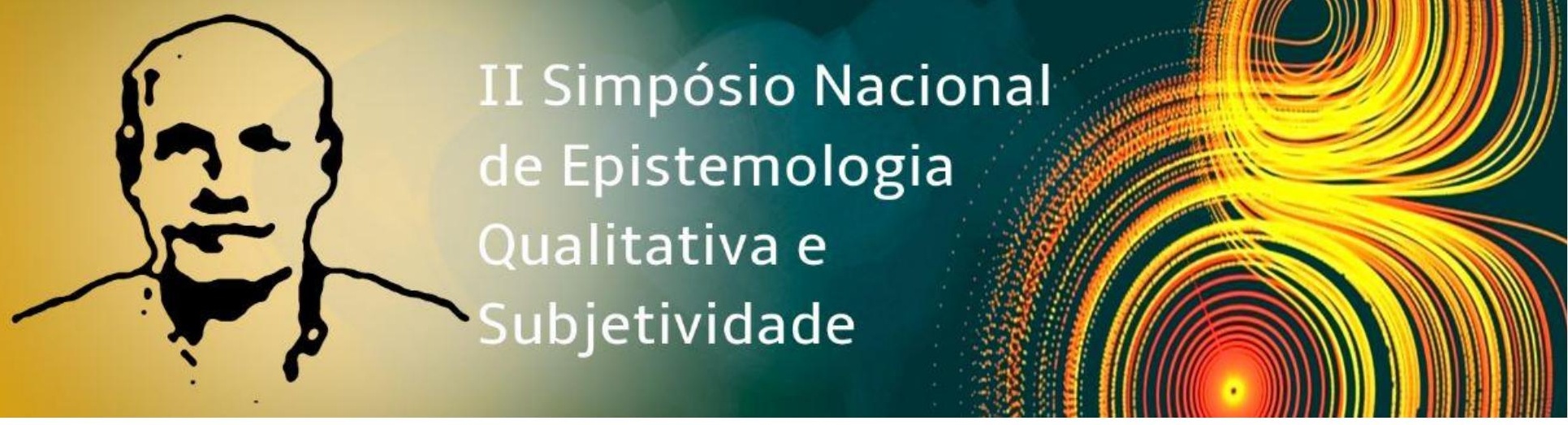

